\title{
Segurança do alimento e economia da rastreabilidade
}

Moisés de Andrade Resende Filho*

RESUMO - O artigo discute a importância da segurança do alimento e os vários tipos de falhas de mercado envolvidos em sua provisão. Defende-se que apesar de não objetivar interferências diretas nos processos produtivos de modo a aumentar a segurança do alimento, a rastreabilidade é uma tecnologia que pode atuar na criação de incentivos ao longo de cadeias produtivas de alimentos e, mesmo, reduzir a probabilidade de exposição dos consumidores a alimentos inapropriados ao consumo. Nesse contexto, a regulamentação do setor de alimentos via a imposição de sistemas de rastreabilidade deve ser uma possibilidade a ser considerada e, portanto, melhor estudada via trabalhos teóricos e empíricos.

Palavras-chave: Segurança do alimento. Falhas de mercado. Rastreabilidade. Regulação.

\section{INTRODUÇÃO}

Questões relacionadas à extensão com que o alimento é seguro para a alimentação humana ou, simplesmente, segurança do alimento vêm se tornando extremamente importantes para consumidores, cada vez mais, preocupados com a própria saúde. Tal proposição tem por base estudos que constataram o efeito depressor da demanda de casos noticiados de problemas com a segurança do alimento (RESENDE FILHO, 2008, PIGGOTT; MARSH, 2004), por exemplo, devido a surtos de zoonoses como a gripe suína e mal da vaca louca; e casos de enfermidades transmitidas por alimentos (ETAs) contaminados com salmonella, listeria, E. coli, trichinae e staphylococcus; e a casos de uso ilegal ou excessivo de hormônios e antibióticos na produção animal. Como exemplos de problemas de segurança do alimento no Brasil, Tavares e Serafini (2006) relatam que ocorreram, entre 1996 e 2000 em São Paulo, 4.581 casos de ETAs por Salmonella, sendo a carne bovina responsável por 11\% desses episódios. Ainda, entre os anos 1997 e 1999, foram noticiados diversos casos de botulismo devido ao consumo de conservas de palmitos no Brasil.

Em março de 1996, comprovou-se definitivamente em laboratório a ligação entre o mal da vaca louca ou Encefalopatia Espongiforme Bovina (BSE ou Bovine Spongiform Encephalopathy) e a nova variante da doença Creutzfeldt-Jakob (vCJD) que, em seres humanos, ataca o sistema nervoso central e é fatal (Nardone, 2003). Tal comprovação ocorre após casos de BSE terem sido evidenciados em bovinos de cerca de 20 países, com mais de

\footnotetext{
* Doutor em Economia Aplicada pela Universidade de Minnesota, EUA. Professor adjunto do Departamento de Análise Econômica da Universidade Federal de Juiz de Fora. Endereço eletrônico: moises.resende@ufjf.edu.br.
} 
90\% dos casos na Grã-Bretanha, onde, exatamente, foram detectados os primeiros casos em 1986. Desde então, a defesa da imposição da rastreabilidade animal como forma de se monitorar a produção ao nível de fazenda vem ganhando força. Isso porque, diferentemente da contaminação bacteriana, o mal da vaca louca origina-se exclusivamente na propriedade agrícola pois é o fornecimento de rações contendo carne e ossos provenientes de animais contaminados que constitui o principal vetor de contaminação de animais sadios com BSE (NARDONE, 2003). Por isso, Souza-Monteiro e Caswell (2004) relatam que a União Européia e o Japão tornaram a rastreabilidade do gado bovino mandatória e, assim, um bem público.

O fato é que a percepção de risco do consumidor com relação ao mal da vaca louca tem feito com que a rastreabilidade animal se tornasse fundamental à sustentação da demanda por carne bovina. Nesse sentido, o primeiro caso confirmado de BSE nos EUA em dezembro de 2003 foi fundamental para acelerar o cronograma da implantação do sistema de rastreabilidade animal dos EUA, denominado de National Animal Identification System (NAIS). Por exemplo, toda a importação de carne dos EUA pelo Japão em 2003 foi embargada após o anúncio do primeiro caso de BSE em uma vaca no Estado de Washington. O Japão somente suspendeu esse embargo em dezembro de 2005, condicionado a que os EUA aprimorassem o programa de testes para detecção de BSE e agilizassem a implantação da rastreabilidade da produção de carne bovina.

Ao contrário de técnicas como Redução de Patógenos ${ }^{45}$ (RP) e Análise de Riscos e Pontos Críticos de Controle ${ }^{46}$ (HACCP), sistemas de rastreabilidade não visam interferir diretamente em procedimentos e processos de modo a aumentar a qualidade ou segurança do alimento. Mesmo quando modificações na linha de produção são necessárias, por exemplo, para limitar a mistura de matérias-primas, não terão sido essas modificações a motivação original para a adoção do sistema de rastreabilidade. Segundo a International Organization for Standardization - ISO (2000) um sistema de rastreabilidade cria a habilidade para se recuperar a história e aplicação ou localização de um artigo ou uma atividade ou um processo por meio de uma identificação registrada. Dessa forma, sistemas de rastreabilidade visam, basicamente, acumular informações sobre atributos do produto, incluindo-se aqui qualidade, segurança e

\footnotetext{
45 Exemplos de procedimento para redução de patógenos seriam a pasteurização, lavagem, irradiação e intervenções químicas em alimentos.

${ }^{46}$ HACCP é um conjunto de procedimentos sistemáticos de controle de perigos potenciais em alimentos, caracterizado pela identificação dos problemas que poderiam ocorrer antes mesmo que ocorram e pelo estabelecimento de medidas de controle em estágios de produção identificados como críticos.
} 
origem, à medida que o mesmo se movimenta ao longo da cadeia produtiva (STARBIRD; AMANOR-BOADU, 2006).

Para que as informações armazenadas num sistema de rastreabilidade possam interferir na segurança do alimento, as mesmas devem ser utilizadas na prevenção da entrada de alimentos sem qualidade ou segurança na cadeia produtiva ou, quando os mesmos, por erro, já entraram na cadeia produtiva, tais informações devem ser utilizadas na retirada do produto com problemas, por exemplo, via recall. As informações armazenadas por um sistema de rastreabilidade também podem ser utilizadas na determinação de responsabilidades em um evento de crise de segurança do alimento, assegurando a devida aplicação da lei (HOBBS, 2004). Nesse sentido, a maior parte dos oponentes à imposição de sistemas de rastreabilidade mandatórios, por exemplo, um sistema nacional de rastreabilidade, menciona com preocupação o aumento de suas responsabilidades e das chances de serem implicados em uma eventual crise de segurança do alimento (SOUZA-MONTEIRO; CASWELL, 2004; GOLAN et al., 2004).

O presente artigo inicialmente discorre sobre os motivadores da adoção voluntária de rastreabilidade pelo setor privado, fazendo as devidas ligações com a questão da provisão de segurança do alimento. Em seguida, trata das possíveis falhas de mercado associadas à provisão de segurança do alimento e do potencial papel da regulação, inclusive com relação à imposição de rastreabilidade. Finalmente, conclui-se com um breve sumário dos principais pontos abordados sobre falhas de mercado na provisão de segurança do alimento, fazendo a ligação, sempre que possível entre o uso da rastreabilidade como peça na regulação visando ao aumento da segurança do alimento.

\section{ADOÇÃO VOLUNTÁRIA DE RASTREABILIDADE DE ALIMENTOS}

A adoção voluntária de sistemas de rastreabilidade tem sido motivada por diversas razões relacionadas à certificação e diferenciação de produtos com atributos credenciais ${ }^{47}$, ao controle de processos de qualidade, à realização de recall precisos e direcionados de produtos, ao aumento da segurança via detecção de fraudes, à adequação a padrões estabelecidos no mercado internacional e ao gerenciamento de complexas cadeias de suprimento (GS1 AISBL, 2009, MOE, 1998). Assim, os sistemas de rastreabilidade diferem entre empresas e países, exatamente, porque os mesmos irão primeiramente considerar os seus objetivos, os custos e

\footnotetext{
${ }^{47}$ Atributo credencial é todo aquele que não pode ser constatado ou determinado pelo consumidor mesmo após o consumo do bem.
} 
benefícios dos sistemas de rastreabilidade disponíveis para só então decidirem sobre o tipo de sistema a ser implementado. Confirmando esse ponto, Trautman, Goddard e Nilsson (2008), em uma ampla revisão de literatura, detectaram que existe completa falta de uma definição precisa de sistemas de rastreabilidade, tornando inviável identificar similaridades e diferenças entre estudos.

Em um estudo sobre o estado da arte da utilização de rastreabilidade no setor de alimentos dos EUA, Golan et al. (2004) detectaram que o setor privado americando tem, voluntariamente, desenvolvido diversificada e significante capacidade para rastrear os alimentos sem a regulamentação governamental. Uma da motivações para tanto é facilitar o rastreamento para trás visando segurança e qualidade dos alimentos, por exemplo, para auxiliar no acompanhamento da distribuição dos produtos e para realizar o recall mais preciso de produtos quando necessário. Também Buhr (2003) detectou, baseando-se em estudos de caso com empresas européias, o papel desempenhado pela rastreabilidade em auxiliar empresas a limitarem o tamanho do recall de produtos em caso de ocorrência de falhas nos produtos. O fato é que sempre é uma tarefa desafiante para um processador ou distribuidor de alimentos identificar corretamente a fonte duma falha no produto para poder, em seguida, deduzir quais outros produtos podem ter sido negativamente afetados por tal falha e rastrear tais produtos. Nesse tocante, um sistema de rastreabilidade poderia rastrear para trás para detectar a fonte dum problema, e rastrear para frente para encontrar todos os outros produtos e estágios de produção com as mesmas propriedades indesejáveis, caso uma falha no produto ocorra (JANSEN-VULLERS; VAN DORP; BEULENS, 2003). Um sistema de rastreabilidade poderia, ainda, auxiliar na identificação precoce de uma falha do produto, propiciando a retirada rápida e precisa de produtos defeituosos da cadeia de suprimentos, reduzindo o perigo à saúde do consumidor e custos para as empresas.

Há interesse das empresas e, portanto, um incentivo privado na realização, quando necessário, do recall preciso de produtos de modo a mitigar custos diretos decorrentes da perda e destruição de produtos defeituosos, notificações do recall, despesas processuais e com a justiça, entre outros gastos. Ademais Thomsen e McKenzie (2001) estimaram que um recall do tipo Class I que é o tipo mais grave, sendo inicializado quando há reais chances de que a ingestão do alimento vá causar problemas de saúde e mesmo morte, reduziu a riqueza dos acionistas das empresas de alimentos envolvidas nesse tipo de recall em 1.5\% e 3\%. Em outras palavras, o dano causado por produtos defeituosos para o consumidor é, em parte, internalizado pelas empresas. 
Empresas também podem ter interesse em adotar rastreabilidade para fortalecer a demanda por seus produtos, por exemplo, no sentido de satisfazer consumidores que associam rastreabilidade a maior segurança do alimento ou que, simplesmente, desejam saber a origem daquilo que consomem. Dickinson e Bailey (2002) observaram em um estudo com leilões em laboratório que os consumidores americanos de carne vermelha podem estar dispostos a pagar por rastreabilidade por si só. Já Hobbs et al. (2005), utilizando experimentos em laboratório com consumidores canadenses, encontram que a rastreabilidade de carnes não adicionou valor ao produto por si só. Tais resultados conflitantes mostram que pode ser possível que não haja incentivo suficiente para que empresas adotem voluntariamente rastreabilidade de modo a fortalecer a demanda pelos seus produtos.

Tem sido reconhecido que a rastreabilidade de alimentos pode atuar na redução do anonimato das empresas, propiciando a melhor distribuição de responsabilidades em cadeias produtivas de alimentos. Nesse sentido, o aumento da probabilidade de que fornecedores de matérias-primas possam ser responsabilizados por falhas no produto pode criar incentivo para que empresas upstream ${ }^{48}$ aumentem os seus esforços em segurança do alimento (POULIOT; SUMNER, 2008). Por exemplo, Resende-Filho e Buhr (2008) demonstraram como a redução no anonimato via rastreabilidade pode ser utilizado por abatedores como uma peça de mecanismos de incentivos. Esses mesmos autores encontraram, com base em simulações numéricas, que mesmo baixa probabilidade de preservação da identidade dos fornecedores (rastreabilidade) e pequenos incentivos monetários podem induzir terminadores de gado a utilizar a tecnologia que causa menores danos à carne processada.

\section{SEGURANÇA DO ALIMENTO E FALHAS DE MERCADO}

Do ponto de vista econômico, o alimento seguro possui características de bem privado uma vez que o consumidor recebe benefício direto ao consumir uma unidade de alimento seguro, eliminando, ao mesmo tempo, a possibilidade de alguém mais consumir essa mesma unidade. Por outro lado, o alimento seguro também possui características de bem público visto que, quando alguém fica doente ou morre devido ao consumo de uma unidade de alimento estragado, criam-se externalidades negativas nos outros agentes da economia. Isso porque os gastos do sistema público de saúde e de seguridade social são cobertos, em última instância, por todos os pagadores de tributos. Diante disso, é possível que o mercado, por si

\footnotetext{
${ }^{48}$ Empresas de cima, à montante, ou para trás.
} 
só, não seja capaz de prover a quantidade socialmente eficiente de segurança do alimento, o que caracterizaria uma falha de mercado. Tal possibilidade justificaria a intervenção pública em termos do estabelecimento de processos e técnicas de fabricação e controle, monitoramento direto da qualidade, aplicação de penas e taxas sobre alimentos detectados como contaminados e subsídios, àqueles detectados como seguros, entre outras medidas. Por exemplo, a União Européia estabelece pela “European regulation 178/2002” um nível obrigatório mínimo de rastreabilidade de alimentos tal que seja possível para empresas e autoridades públicas retirarem rapidamente produtos do mercado (CHARLIER; VALCESCHINI, 2008).

Crises de falta de segurança do alimento, apesar de causarem impactos negativos sobre os custos e valor das empresas individualmente, podem também causar impactos negativos, via transbordamentos, no valor acionário e na demanda de todo o setor ao qual a empresa pertence. Tal fato pode ser mais um fator causador de falhas de mercado na provisão de segurança do alimento. Isso porque ao possuir características de "common good", ou seja, pertencer a todas as empresas do setor, a segurança do alimento cria incentivos para empresas se comportarem como "free-riders". Nesse caso, os "free-riders" tenderão a investir menos do que seria socialmente ótimo na provisão de segurança de alimento, pegando carona no investimento das demais empresas do setor. Tal comportamento, provavelmente levará o setor, como um todo, a ofertar uma quantidade de segurança do alimento inferior ao socialmente ótimo, o que constitui uma falha de mercados nos moldes de uma "tragédia dos comuns".

As cadeias produtivas de alimentos são normalmente constituídas por segmentos independentes, o que faz com que esforços realizados por empresas upstream no controle de qualidade e segurança do alimento não sejam diretamente observados pelas empresas downstream $^{49}$. Com o monitoramento das empresas upstream tecnicamente inviável ou proibitivamente caro, os resultados dos esforços em segurança do alimento serão observável apenas em estágios downstream da cadeia produtiva em que, muito provavelmente, a identidade dos fornecedores já foi perdida. Como consequência disso, o sinal do esforço não poderá ser associado com aqueles que executaram o esforço. Dessa forma, o anonimato característico das cadeias produtivas de alimentos acaba por impossibilitar as possibilidade de aplicação de incentivos baseados em punições e recompensas, o que potencialmente gera o provimento subótimo de segurança do alimento ou falha de mercado decorrente da assimetria de

${ }^{49}$ Empresas de baixo, para frente, ou à jusante. 
informação. Nesse sentido, haveria um incentivo para que empresas implementassem protocolos de produção formalizados em cláusulas contratuais e utilizassem a tecnologia da informação no gerenciamento de cadeias de suprimentos. Em última instância, tais iniciativas visam aumentar as chances de que as identidades de produtos e fornecedores sejam preservadas ao longo da cadeia produtiva e caracterizam o que se entende por rastreabilidade. De fato, segundo Hobbs (2004) a habilidade de rastrear produtos facilita a detecção dos responsáveis por problemas de crises na segurança do alimento. Tal habilidade foi denominada por essa autora de função responsabilidade ou liability function dos sistemas de rastreabilidade.

\section{CONCLUSÕES}

A segurança do alimento tem se tornado preocupação generalizada de consumidores e governos nos últimos tempos. Como a segurança do alimento apresenta característica de atributo credencial, torna menos eficiente a regulação e controle do próprio mercado com base em sua observação. Com base nisso seria justificada a regulação focada muito mais sobre procedimentos e processos adotados pelo setor de alimentos do que em níveis prédeterminados de segurança do alimento.

A segurança do alimento é também um “common good” para setores produtores de alimentos, o que suscita o aparecimento de free-riders, ou seja, empresas que investem pouco em segurança do alimento e que se beneficiariam dos potenciais esforços feitos por outras empresas do setor. Diante disso, é de se esperar que os estímulos do mercado para setores produtores de alimentos sejam insuficiente para que os mesmos ofertem segurança do alimento em uma quantidade condizente com nível socialmente ótimo, suscitando assim, mais uma razão para a potencial regulação. Por exemplo, ao se impor rastreabilidade obrigatória ao setor de alimentos, força-se cada empresa individual do setor a realizar investimento na implementação do seu sistema de rastreabilidade. Diante disso, espera-se que tais empresas utilizem tal investimento para auferirem benefícios, por exemplo, podem direcionar os seus sistemas de rastreabilidade para a realização de recalls mais direcionados, rápidos e precisos de produtos impróprios ao consumo, aumentando a segurança do alimento.

A segurança do alimento também apresenta aspectos de bem público uma vez que danos à saúde dos consumidores causados pela ingestão de alimento inapropriado gera externalidades negativas em toda a sociedade. Dessa forma, os custos de crises de segurança do alimento não são totalmente internalizados pelas empresas, gerando mais um fator 
responsável pela provisão subótima de segurança do alimento. Nesse tocante, a regulação poderia atuar, por exemplo, aplicando penas mais severas em caso de incidentes envolvendo crises de segurança de alimento, fazendo com que o custo privado de tais crises se aproximasse do custo social.

Finalmente, os esforços em segurança do alimento das empresas envolvidas na produção de alimentos não são perfeitamente verificáveis, o que gera dificuldades na criação de incentivos ao longo das cadeias produtivas. Como conseqüência, haveria incentivo para que o setor privado utilizasse rastreabilidade de modo a permitir a criação de mecanismos baseados em incentivos e punições ao longo de cadeias produtivas. Como resultado final, os esforços em segurança do alimento seriam mais próximos daqueles socialmente eficientes, mitigando falhas de mercado decorrentes da assimetria de informação entre os diversos segmentos da cadeia produtiva.

Por tudo isso, apesar de não objetivar interferências diretas nos processos produtivos de modo a aumentar a segurança do alimento, a rastreabilidade pode atuar no sentido de se criar incentivos ao longo da cadeia produtiva de alimentos e, mesmo, reduzir a probabilidade de exposição dos consumidores a alimentos inapropriados. Assim, dadas as diversas possibilidades de falha de mercado na provisão de segurança do alimento, a regulamentação do setor de alimentos via imposição de sistemas de rastreabilidade deve ser uma possibilidade a ser melhor considerada e, portanto, melhor estudada.

\section{REFERÊNCIAS}

BUHR, B.L. Traceability and information technology in the meat supply chain: implications for firm organization and market structure. Journal of Food Distribution Research, v. 34, n. 3, p. 13-26, 2003.

CHARLIER, C., VALCESCHINI, E. Coordination for traceability in the food chain. A critical appraisal of European regulation. European Journal of Law and Economics, v.25, n.1, p.1 -15, 2008.

DICKINSON, D.L., BAILEY, D. Meat traceability: Are U.S. consumers willing to pay for it? Journal of Agricultural and Resource Economics, v. 27, n.2, p. 348-364, 2002.

GOLAN, E. B., KRISSOFF, F., KUCHLER, L., CALVIN, K. N., PRICE, G. Traceability in the U.S. food supply: Economic theory and industry studies. Agricultural Economic Report No. 830, U.S. Department of Agriculture/Economic Research Service, Washington, DC, March 2004.

GS1 AISBL. Traceability - What's in it for you. Brussels: GS1, 2009. Disponível em: <http://www.gs1.org/docs/traceability/traceability_brochure.pdf>. Acesso em: abril, 2009.

HOBBS, J.E. Information asymmetry and the role of traceability systems. Agribusiness: An International Journal, v. 20, n. 4, p. 397-415, 2004. 
HOBBS, J.E., BAILEY , D., DICKINSON, D., HAGHIRI , M. Traceability in the Canadian red meat market sector: Do consumers care? Canadian Journal of Agricultural Economics, v.53, n.1, p. 47-65, 2005.

INTERNATIONAL ORGANIZATION FOR STANDARDIZATION, ISO 9000:2000. (2000). Quality management systems: Fundamentals and vocabulary. Brussels, Belgium. European Standard, Committee for Standardization, EN ISO 9000:2000, Point 3.5.4..

JANSEN-VULLERS, M.H., van DORP , C.A., Beulens, A.J.M. Managing traceability information in manufacture. International Journal of Information Management, v. 23, n.5, p.395-413, 2003.

MOE, T. Perspectives on traceability in food manufacture. Trends in Food Science \& Technology, v. 9, 211-4, 1998.

NARDONE, A. Impact of BSE on livestock production system. Veterinary Research Communications, v. 27, Supplemento 1, p. 39-52, 2003.

PIGGOTT, N.E., MARSH, T.L. Does food safety information impact U.S. meat demand? American Journal of Agricultural Economics, v.86, n.1, p.154-74, 2004.

POULIOT, S., SUMNER, D.A. Traceability, liability and incentives for food safety and quality. American Journal of Agricultural Economics, v.90, n.1, p.15-27, 2008.

RESENDE FILHO, M.A. Potenciais benefícios do sistema de rastreabilidade animal dos EUA para o setor de carnes americano. Revista de Economia e Sociologia Rural, v.46, n.4, p. 1129-1154, 2008.

RESENDE FILHO, M.A., BUHR, B.L.. A principal-agent model for evaluating the economic value of a traceability system: a case study with injection-site lesion control in fed cattle. American Journal of Agricultural Economics, v. 90, n. 4, p.1091-1102, 2008.

SOUZA-MONTEIRO, D.M., CASWELL, J.A. The Economic of Implementing Traceability in Beef Supply Chains: Trends in Major Producing and Trading Countries, Working Paper No. 2004-6, ed. Amherst, MA: University of Massachusetts Amherst, Department of Resource Economics, 2004.

STARBIRD, S.A., AMANOR-BOADU, V. Do inspection and traceability provide incentives for food safety? Journal of Agricultural and Resource Economics, v. 31, n. 1, p.14-26, 2006.

TAVARES, T. M., SERAFINI, A.B. Carnes de hambúrgueres prontas para consumo: aspectos legais e riscos bacterianos. Revista de Patologia Tropical, v. 35, n. 1, p. 1-21, 2006.

THOMSEN, M.R., MCKENZIE, A.M. Market incentives for safe foods: an examination of shareholder losses from meat and poultry recalls. American Journal of Agricultural Economics, v. 83, n.3 ,p.526-538, 2001.

TRAUTMAN, D., GODDARD, E., NILSSON, T. Traceability - A Literature Review. Department of Rural Economy, University of Alberta Project Report 08-02, 2008. Disponível em: < http://www.uofaweb.ualberta.ca/re/pdfs/08_02_final.pdf>. Acesso em: abril 2009. 
